\title{
Chronic renal disease in Mexico: A preventive uncontrolled epidemic
}

\author{
Nasser A. Polanco-Flores ${ }^{1,2 *}$ \\ ${ }^{1}$ Consultorio Especializado en Enfermedades Renales (CEER), Clínica Cervantes, Tula de Allende, Hidalgo; ${ }^{2}$ Departamento de Medicina Interna, \\ Instituto de Salud del Estado de México (ISEM), Estado de México. México
}

\begin{abstract}
Diabetic and hypertensive nephropathy are the leading causes of chronic kidney disease (CKD) and renal replacement therapy worldwide, due to the accelerated deterioration in renal function suffered by patients who fail to meet metabolic control and blood pressure targets, respectively, as well as associated comorbidities that contribute as additional factors of progression, causing a dramatic drop in the glomerular filtration rate with subsequent need for dialysis therapy. Given this scenario, it is paradoxical that there are no preventive programs aimed at the early detection of nephropathy in the general consultation at the different health-care levels, which ultimately leads to a delayed referral to the kidney specialist. If we consider persistent hyperglycemia and abnormally high blood pressure rates as the main triggers for the progression of incipient nephropathy up to the advanced stage, CKD is classified as a preventable disease, if greater medical intervention in the first and second level of care was available, as this would change the evolution of the disease in patients.
\end{abstract}

Key words: Epidemics. Kidney failure. Disease prevention. Primary prevention. Straining. Mass screening.

\section{Introduction}

Chronic kidney disease (CKD) is a condition that has been progressively on the rise in regard to its incidence and prevalence in recent years, as it affects more than $10 \%$ of the world population. It is currently classified as a global epidemic ${ }^{1}$. Even though not all countries have statistics on CKD, the Unites States Renal Data System has registered an exponential increase in the incidence of this disease per million inhabitants, going from 74,917 patients in 1996 to 118,014 patients in 2014. From this total, $44.2 \%$ of patients suffered from diabetic nephropathy (DN) and $28.6 \%$ from hypertensive nephropathy $(\mathrm{HN})$, affecting the age group of $45-74$ years in greater proportion $(64.4 \%)$, which implies that preventive measures should be in place for younger age groups to avoid this unprecedented increase in advanced CKD that has been witnessed in the past three decades, which magnifies morbidity and mortality in patients ${ }^{2}$. Notwithstanding, these data mostly correspond to the non-Hispanic population $(86.5 \%)$; the trend is similar in the European continent.

There is no database on CKD patients in the entire Mexican Republic, with CKD cases being underreported nationwide. Although some efforts have been made to understand our domestic epidemiology and whose results are not far from those aforementioned, there are data showing a higher incidence of reporting rates in some states such as Jalisco and Morelos that surpass the US and European incidence rates ${ }^{2-4}$.
Correspondence:

*Nasser A. Polanco-Flores

E-mail: nasser_abdel2000@yahoo.com
Available online: 17-10-2019 Rev Med Hosp Gen Mex. 2019;82(4):194-197 www.hospitalgeneral.mx under the CC BY-NC-ND license (http://creativecommons.org/licenses/by-nc-nd/4.0/). 
Considering that diabetes mellitus (DM) and systemic arterial hypertension $(\mathrm{SAH})$ represent the main cause of CKD worldwide, efforts should be focused on primary and secondary health care, with a preventive approach in the care of patients. However, there is no program with this approach for this population to date, especially from a nephrological viewpoint. This leads to a high prevalence and incidence of late diagnosed advanced cases that require dialysis therapy, thus increasing the associated morbidity and mortality, health costs, reduced quality of life, and life expectancy of patients.

\section{CKD epidemiology}

In Europe, CKD incidence is clearly lower than the US rate; an annual increase close to $5 \%$ has been detected, with an increase of approx. 5000-6000 new patients starting renal replacement therapy every year. About $23.1 \%$ of these cases are due to DM and $15.2 \%$ due to $\mathrm{SAH}$, affecting the population aged 45-74 years by $60 \%{ }^{3}$.

Although there are no data available on the overall incidence of this disease over the past decade, comparative data from 2014 stand out, where an incidence rate of 421.2 (per million/year) in Jalisco, Mexico, is much higher than that of the United States and Spain, which is only second to the Taiwanese rate standing at 455.0 (per million/year). It is worth mentioning that Mexico leads the world comparatively as the country with the highest incidence rate of advanced DN for 2014 at 244.2 , with a rate of $117 \%$ since 2001 , which continues to rise according to projections made ${ }^{3}$. These estimates sadly are not destined to change unless actual efforts are made to focus on early detection and treatment of diseases such as DM 2 and hypertension.

There is no database system such as the US and European databases in the Mexican Republic, which helps knowing our epidemiology of CKD. Some attempts have been made in this regard, highlighting that in 2009, a social security study was conducted from a database of more than 31,000 patients, which concluded that CKD causes ranged from DM at $48.5 \%$, arterial hypertension at $19 \%$, chronic glomerulopathy at $12.7 \%$, and other causes at $19.8 \%$, with an estimated CKD prevalence of 495 cases per million inhabitants ${ }^{4}$. Likewise, the results of the Mexican version of a pilot program called Kidney Early Evaluation Program Mexico were published in 2010, which consisted of screening the entire population at a high risk of developing CKD (adults with diabetes, hypertension, and family history of diabetes-hypertension-CKD). This screening took place in only two states: Mexico City and Jalisco, with a total population of 3539 patients, which detected a prevalence of CKD of $26 \%$ and $33 \%$, respectively, which was associated with a higher prevalence of diabetes and hypertension in the population of Jalisco ${ }^{5}$.

Despite the existence of a sub-database of patients suffering from this disease in Mexico, the history is similar and even worse, considering the high prevalence of obesity, diabetes, and SAH reported by the Encuesta Nacional de Salud y Nutrición (National Survey of Health and Nutrition) (ENSANUT, 2016), with the highest increase in the percentage of patients diagnosed overtime; a prevalence of $9.4 \%$ for patients with DM, $25.5 \%$ for patients with arterial hypertension, and $72.5 \%$ for those overweight-obese patients has been found. This is in fact underreported and should garner more attention by the department of health, considering that it is a metabolic problem with a major impact on the health status of the Mexican population, including cardiovascular diseases and $\mathrm{CKD}^{6}$.

According to INEGI data, CKD as a cause of death has been ultimately gaining prominence in the past decades, going from thirteenth place in 2000 to tenth place in 2016 ( $2 \%$ total mortality). This is due to the growing number of metabolic diseases as DM that currently ranks second nationally with $15 \%$ of total mortality.

\section{Health costs associated with dialysis treatment versus prevention}

In Mexico, except for a couple of states, public health institutions do not include dialysis treatment in their health-care programs, as kidney disease is deemed a preventable disease. However, these programs cover other conditions that also exhibit this feature, such as cardiovascular diseases and sexually transmitted diseases, among others described in public health-care programs. These include some high-cost conditions such as cancers, leukemia, corneal, and bone marrow transplants that may lead to overspending and, consequently, the impoverishment of Mexican families.

CKD, in its advanced stage, forces patients to depend on renal replacement therapy to remain alive. The majority of patients only have two options: peritoneal dialysis or hemodialysis. This means that treatment costs are financed by private sources in most states. Regarding monthly costs, it is estimated that an average patient would spend approx. 7000-12,000 Mexican pesos in peritoneal dialysis. This would also depend on 


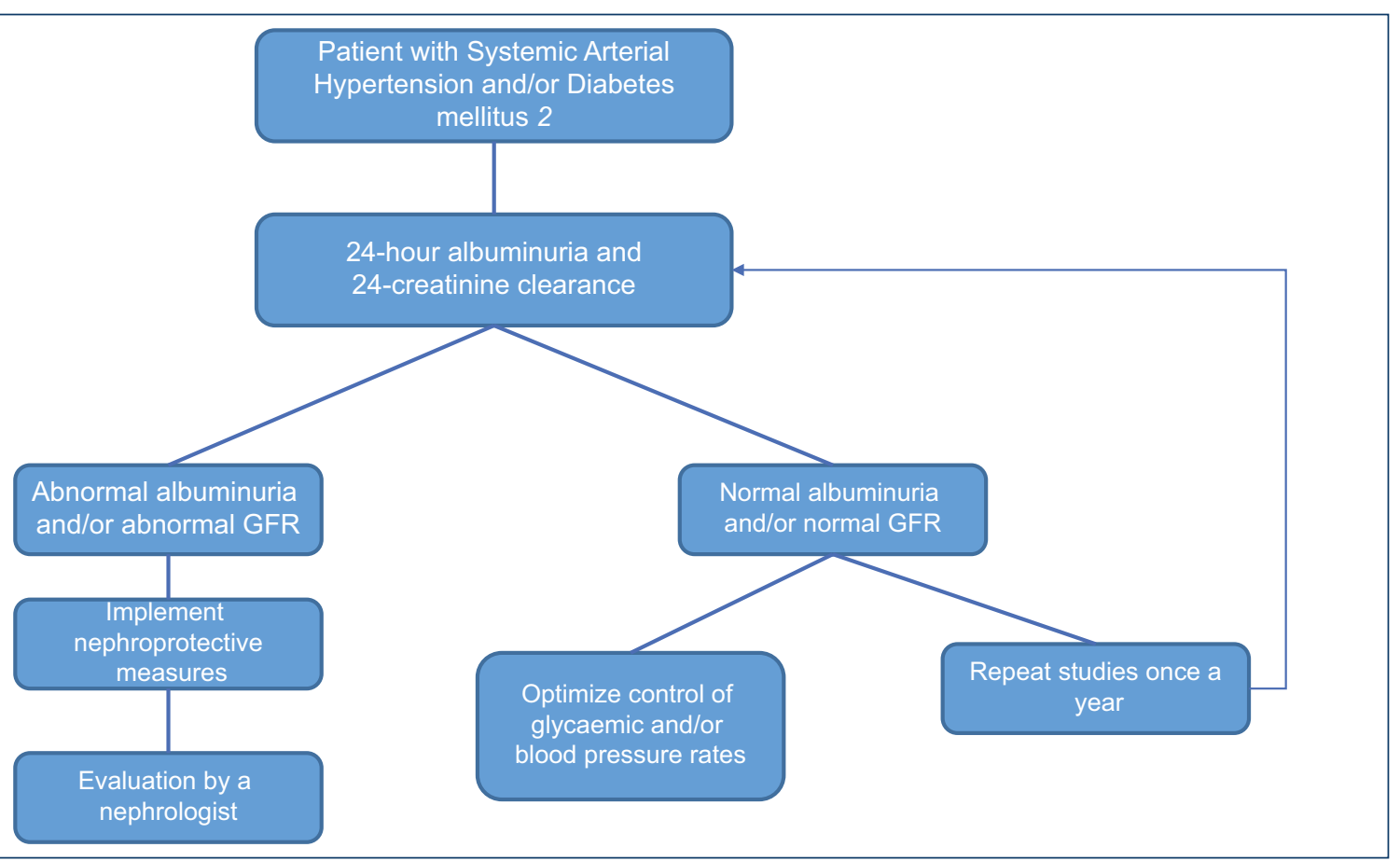

Figure 1. Proposed care flow chart for screening early hypertensive and/or diabetic nephropathy, regardless of the stage of disease progression.

the type of brand of dialysate bag used. In addition, if the patient is on hemodialysis, this cost rises to 16,000 18,000 Mexican pesos/month, taking into account the minimum cost per session available in most private health-care establishments nationwide. Due to this brief cost analysis, advanced CKD is deemed a disease that heavily impacts family income, often in a catastrophic manner, and should be included with other diseases that are currently covered by public healthcare programs in all Mexican states.

If this monthly expense is multiplied over 12 months of treatment uninterruptedly so that patients are able to live, taking into account the estimated size of population that can be treated in the health sector, this item of expenditure is impressive, even considering how CKD is underreported in Mexico. In this sense, it sounds logical not to include CKD in the list of diseases covered by public health-care programs, but then, no other efforts are being implemented to reduce its incidence and prevalence as an advanced disease that requires dialysis as palliative care.

Thus, given this prospect, it is cheaper to conduct a screening study at primary and secondary health-care level in a correct manner for the entire population at risk of suffering from CKD, taking into account that the first two causes are DM 2 and SAH. This will allow timely detection and referral with specialists to establish nephroprotective measures. On average, the total cost of screening ranges from 250 to 500 Mexican pesos in private laboratories, which may represent a lower cost in intramural laboratories or those covered by external agreements. Such a study would be carried out once a year in patients, costing much less than the total cost that would be spent in dialysis as palliative care.

\section{Targeted search of cases}

This implies a change of mental attitude in health professionals, by avoiding the traditional practice of referring DM2 and SAH patients to kidney specialists with delay. In case of hyperazotemia, a significant drop in the glomerular filtration rate (GFR $<30 \mathrm{ml} / \mathrm{min} / \mathrm{sc}$ ) and proteinuria occurs in the overall analysis of urine or albuminuria of difficult control ${ }^{7-10}$. This is a stark prospect, at all levels of the public health care and social security system, where the lack of vision regarding the preventive care of patients with DM2 and SAH has given rise to an exponential increase in $\mathrm{DN} / \mathrm{HN}$ cases without timely care. This ultimately leads to dialysis treatment without an assessment by the kidney specialist, a fact that feeds statistics and institutional expenses in palliative care in recent decades. 
Conventionally, the role of the kidney specialist has been that of a "therapeutic interventionist" with a palliative approach, dedicated to replacing the renal function of patients with $\mathrm{DN} / \mathrm{HN}$ or preparing them for such when they are referred at an advanced stage. A preventive program should be aimed at avoiding this approach although these are usually intended for primary and secondary levels of care, the direction of these programs can be assumed from a tertiary level with an active participation of the nephrologist. Thus, this would change the evolution of patients that are already affected (secondary and tertiary prevention) and positively influence those with a risk factor (primary prevention).

CKD stemming from diabetes and hypertension is a preventable disease, based on the premise that its main risk factor is persistent hyperglycemia and high blood pressure rates, which constitute the "weak spot" of non-controlled patients. Optimal management of these patients enables them to avoid structural changes in renal tissue that leads to subsequent "microalbuminuria", glomerular sclerosis, and inevitable drop in GFR until they reach dialysis therapy. Part of the institutional resources available for primary and secondary prevention should be used, as a priority, in exchange for the traditional tertiary prevention that has proven to be ineffective in controlling the incidence and prevalence of DN as a disease that leads to dialysis therapy over the years.

Thus, CKD as a disease should be approached with greater responsibility, by means of a targeted search of cases of all diabetic and hypertensive patients through appropriate laboratories looking for urinary alterations and/or reduced GFR (24-h microalbuminuria, 24-h creatinine clearance, and general urinalysis), regardless of the time of evolution of their disease, with timely referral to the trained nephrologist or internist so that proper management is followed, focused on delaying the progression and optimizing the management of their blood pressure and glycemia. These studies should be repeated every 12 months in those patients with albuminuria in normal ranges, considering $\leq 25 \mathrm{mg}$ in $24 \mathrm{~h}$ (Fig. 1). It is worth noting that working under this preventive perspective has a greater cost-effective ratio than the costs of chronic renal replacement therapy.

\section{Conclusions}

Advanced CKD caused by diabetes and hypertension can be preventable, provided that it is detected early and changes in treatment or management are possible, something that is achieved only with greater medical intervention at the primary and secondary health-care stage, focusing on meeting metabolic control targets, optimizing blood pressure rates, and reducing other risk factors for progression.

\section{Conflicts of interest}

The author declares not to have any conflicts of interest.

\section{Ethical disclosures}

Protection of human and animal subjects. The authors declare that no experiments were performed on humans or animals for this study.

Confidentiality of data. The authors declare that no patient data appear in this article.

Right to privacy and informed consent. The authors declare that no patient data appear in this article.

\section{References}

1. Eckardt KU, Coresh J, Devuyst O, Johnson RJ, Köttgen A, Levey AS, et al. Evolving importance of kidney disease: from subspecialty to globa health burden. Lancet. 2013;382:158-69.

2. Annual Data Report 2012 De Unites States Renal Data System. Available from: http://www.usrds.org/adr.html. [Last accessed on 2017 Aug 22]

3. Informe Anual Del Registro SEN-ONT De Enfermos Renales (GRER) XLVI Congreso Anual SEN, Octubre 2016, Oviedo. Registro de la Sociedad Española de Nefrología. Available from: http://www.senefro.org. [Last accessed on 2017 Aug 22]

4. Méndez-Durán A, Méndez-Bueno J, Tapia-Yáñez T, Montes AM, Aguilar-Sánchez L. Epidemiología de la insuficiencia renal crónica en México. Dial Traspl. 2010;31:7-11.

5. Obrador GT, García-García G, Villa AR, Rubilar X, Olvera N, Ferreira E, et al. Prevalence of chronic kidney disease in the kidney early evaluation program (KEEP) México and comparison with KEEP US. Kidney Int Suppl. 2010;116:S2-8

6. Encuesta Nacional De Salud Y Nutrición De Medio Camino 2016 (ENSANUT MC 2016), Informe Final De Resultados. Instituto Nacional de Salud Pública, Secretaría De Salud México, publicado 31/10/16. Available from: https://www.ensanut.insp.mx/ensanut2016/index.php. [Last accessed on 2018 Aug 01]

7. American Diabetes Association. Standards of medical care in diabetes 2015. Diabetes Care. 2015;38 Suppl 1:S1-94.

8. Asociación Latinoamericana De Diabetes. Prevención, Diagnóstico Y Tratamiento Temprano De La Nefropatía Diabética. Recomendaciones De La Asociación Latinoamericana De Diabetes (ALAD) Avalado Por La Sociedad Latinoamericana De Nefrología e Hipertensión (SLANH). Consensos ALAD, 2016. Available from: http://www.alad-americalatina.org/ wp-content/uploads/2016/10/PREVENCION-DE-NEFROPATIA. [Last accessed on 2017 Dec 10.

9. Whelton PK, Carey RM, Aronow WS, Casey DE Jr., Collins KJ, Dennison Himmelfarb C, et al 2017 ACC/AHA/AAPA/ABC/ACPM/AGS/APhA/ASH/ ASPC/NMA/PCNA guideline for the prevention, detection, evaluation, and management of high blood pressure in adults: executive summary: a report of the American college of cardiology/American heart association task force on clinical practice guidelines. Hypertension. 2018;71:1269-324.

10. Guía De Práctica Clínica Prevención. Diagnóstico Y Tratamiento De La Enfermedad Renal Crónica Temprana. México: Secretaría De Salud; 2009. 